\title{
Research on the Rolling Motion and Pitch Motion of Planing Boat Sheng ZHANG ${ }^{1, a^{*}}$, Zi-Fan WEl ${ }^{2, b}$, Song-Lin YANG ${ }^{3, c}$ \\ 1,2,3 Jiangsu University of Science and Technology, Zhenjiang, Jiangsu, 212003, China \\ azhangsheng_1990@163.com, bjkdwzf@163.com, cysl560516@vip.com \\ ${ }^{*}$ Corresponding author
}

Keywords: Planing Boat, Rolling Motion, Pitching Motion, Free Decay, Different Draft.

\begin{abstract}
In this paper, a planing boat has been selected as the research object, which has been used as a model to make a new model by scaling. And the free decay experiments have been conducted under different states including different rolling angle, different pitching angle and different ship's draft, whose corresponding mathematical models have been established according to the characteristics of the planing boat. A identification system using optimization concept has been used to identify the experimental data, which finally obtained the variation law of hydrodynamic derivatives. And the hydrodynamic coefficients related have been obtained by the later analyzing the data. The results and the methods of studying the planing boat can provide basis for the improvement in the navigating performance of the planing boat.
\end{abstract}

\section{Introduction}

As a modern high-performance planing hull vessels in a ship, with its good speed and appearance to win more and more attention. Though planing boat has good fast and aesthetics, its navigating performance not good[1]. There are two main methods for the ship hydrodynamic coefficients: theoretical modeling and use identification program.

In the analysis of the model, using the identification system to research rolling and pitching motion of hydrodynamic derivatives. In this paper a method of scaling and the basis of the planing boat, according to the rolling and pitching motion of dynamic balance principle, a mathematic model of the rolling motion, identify the design variables, and using the VB language is compiled based on the principle of optimization algorithm of the planing boat roll and pitch motion model of system identification procedures. Through identification program gets the motion mathematical model of the planing boat, analysis the free decay of boat $[2,3,4]$.

\section{Identification Method of Rolling Motion and Pitching Motion}

\section{Identification Method of Rolling Motion}

Depending balance principle role in the boat at any time on the $\mathrm{x}$-axis torque mode sum to zero, both the following balance equation[5]:

$$
M(\ddot{\phi})+M(\dot{\phi})+M(\phi)=0
$$

According to planing craft on the damping torque analysis combined experimental program, the establishment of the following planing hull seakeeping mathematical model:

$$
\begin{aligned}
& I_{\mathrm{x}} \ddot{\phi}+2 N_{\phi} \dot{\phi}+W|\dot{\phi}| \dot{\phi}+x \dot{\phi}^{3}+D h \sin \phi=0 \\
& \ddot{\phi}+\frac{2 N_{\phi}}{I_{X}} \dot{\phi}+\frac{W}{I_{X}}|\dot{\phi}| \dot{\phi}+\frac{x}{I_{X}} \dot{\phi}^{3}+\frac{D h}{I_{X}} \sin \phi=0
\end{aligned}
$$


Where: $I_{X}$-The total rolling motion moment of inertia; $\phi —$ rolling angle; $\dot{\phi}$ —rolling angular velocity; $\ddot{\phi} \longrightarrow$ roll angular acceleration; $N_{\phi} \longrightarrow$ non-liner roll damping moment coefficient; $W$ — nonlinear roll damping coefficient; $D —$ displacement; $h$ —initial stability.

\section{Identification Method of Pitching Motion}

The planing boat pitching motion similar to rolling motion:

$$
\ddot{\phi}+\frac{2 N_{\phi}}{I_{Y}} \dot{\phi}+\frac{W}{I_{Y}}|\dot{\phi}| \dot{\phi}+\frac{x}{I_{Y}} \dot{\phi}^{3}+\frac{D h}{I_{Y}} \sin \phi=0
$$

Where: $I_{Y} \longrightarrow$ The total pitching motion moment of inertia;

In order to analyze the coefficient, must measure $\phi, \dot{\phi}, \ddot{\phi}$, the sensor can measure $\phi$. Sensor can measure data per 0.01 second then using micro-element method can slove this problem.

\section{Experimental Content}

The real ship was scaled down, and the model made out for experiment (Scaling is 1:3, figure 1). The experiment was conducted in wave-making basin, in Jiangsu University of Science and Technology. In the experiment, the longitudinal direction of ship is perpendicular to the long side of the basin. Experiment, only a flexible cable to connect with the boat and computer, so that the ship completely in six degrees of freedom sway damping movement.
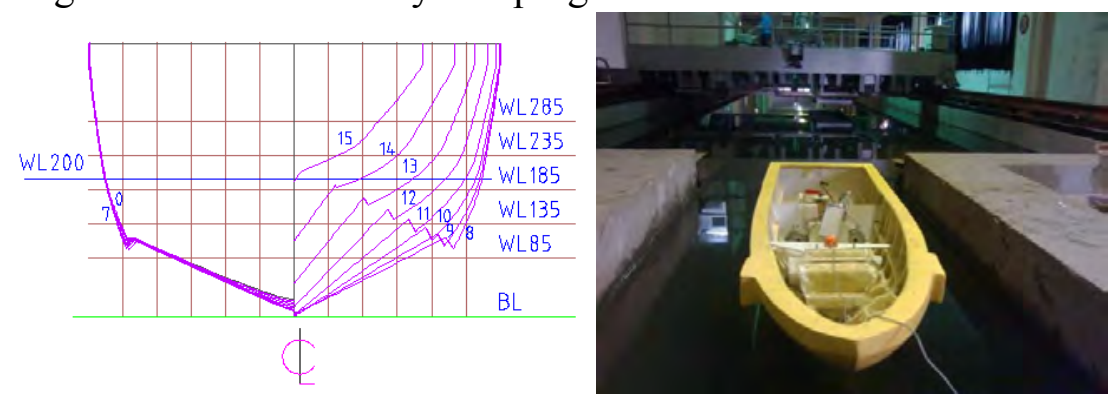

Fig. 1 Lines Plan and Ship Model

The scale of real ship and model ship, as follow:

Tab. 1 Parameter of Real Ship and Model

\begin{tabular}{llll}
\hline Real ship & Parameter $(\mathrm{m})$ & Model ship & Parameter $(\mathrm{m})$ \\
\hline Length & 5.8 & Length & 1.94 \\
Breadth & 1.72 & Breadth & 0.61 \\
Molded depth & 0.65 & Molded depth & 0.5 \\
Draft & 0.6 & Draft & 0.2 \\
$\mathrm{Cb}$ & 0.426 & $\mathrm{Cb}$ & 0.426 \\
\hline
\end{tabular}

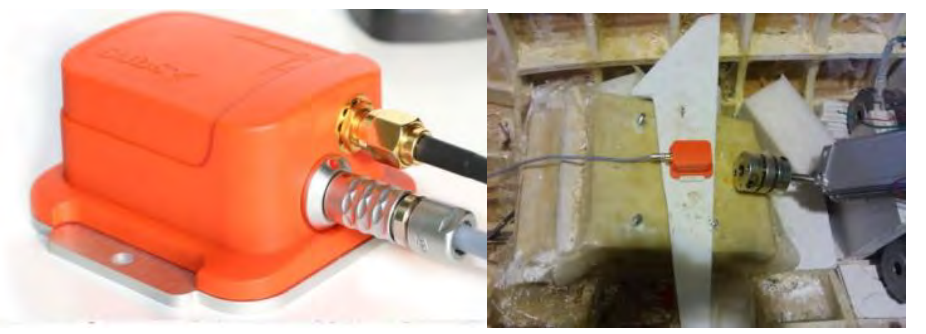

Fig.2 Inertial Measurement System and Location of Sensor 
MTi-G was used in experiment. The sensor is an integrated miniature GPS signal inertial measurement systems. By processing the output attitude and heading information inside the microprocessor. It can provide accurate real-time position and velocity information filtering.

\section{The Rolling Decay Experiment}

In order to get the best data of rolling decay, the longitudinal direction of ship model was perpendicular to the long side of basin, and ensure that the basin wall did no effect on the ship rolling (the long side of basin: the length of model=20:1, figure4), because the wave arose by rolling motion was absorbed by wave absorbing structure. At the same time, the part to connect ship model and sensor used flexible data cable in order to reduce the affect of rolling decay. The ship model was pressure to the initial roll angle, then quickly let go to measure.

\section{The Pitching Decay Experiment}

In order to get the best data of pitching decay, the longitudinal direction of ship model was parallel to the long side of basin, ensure that the basin wall did no affect to pitching motion, at the same time, the part to connect ship model and sensor used flexible data cable in order to reduce the affect of pitching decay. The ship model was pressure to the initial pitch angle, then quickly let go to measure.

\section{The Experiment Of Different Draft}

Because of the large displacement, $20 \mathrm{~kg}$ ballast was put in cabin. The different draft conditions was set in a reasonable rang. No matter in which condition, the float state of structure was consistent, this measure ensure the accuracy of data.

\section{Results and Analysis of Experiment}

Because genetic algorithms was joined in identification program, and genetic algorithms calculating progress is random, this phenomenon cause that the hydrodynamic coefficients calculated was not equal to the data calculated next times. In this paper, hydrodynamic coefficients was calculated five times and find the average[6].

\section{Results and Analysis of Rolling Motion}

Experiment of every initial roll angle was taken 2 3 times, the best data was adopted to analyze. The initial angle was given by human hand and sensor accuracy is high, thus every data was very close to the set ones. The decay curves of different initial roll angle show as following pictures.(The red lines represent roll angle, the blue lines replace roll angular velocity. Some lines is plane at first several time, because worker had not let go. The same meaning as all following pictures.)

Different initial roll angle decay curves, as figure 6:

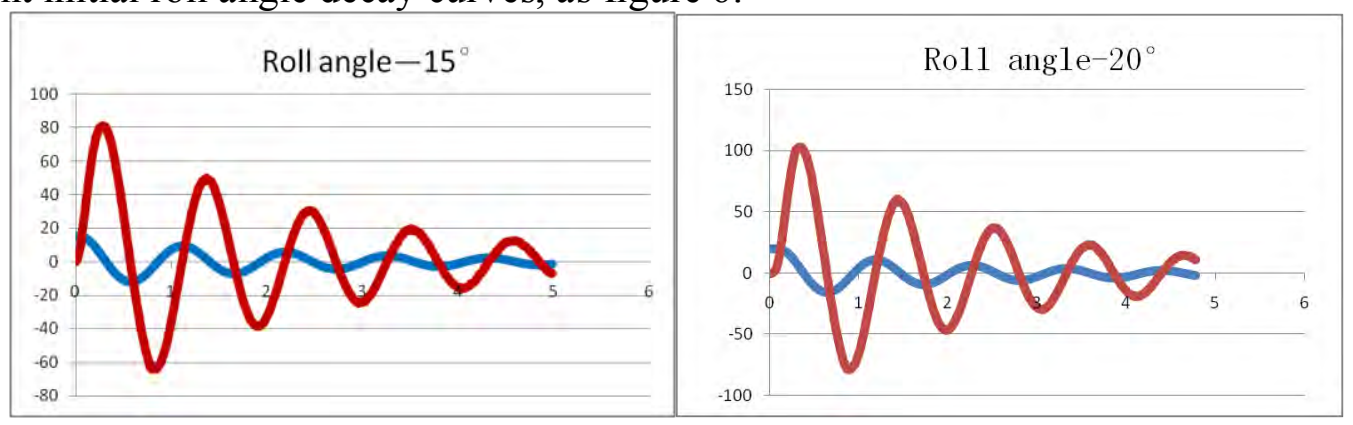

Fig. 3 Different Initial Roll Angle Decay Curves

The four pictures above show different decay angle and angular velocity. From figures can draw this conclusion: free decay frequency is consistent.(X-axis is the time, $\mathrm{Y}$-axis is the roll angle.)

After analyzing the period of rolling motion, using identification program can we get damping coefficient of rolling motion of the planing boat[7]. Quadratic coefficient and cubical coefficient are set out as following form and figure. 


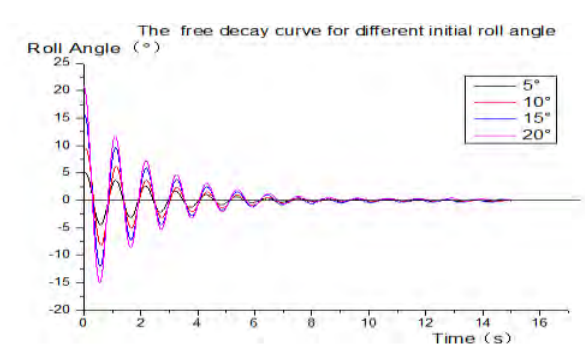

Fig. 4 The Comparison Chart of Free Rolling Decay

Tab. 2 Non-liner Damping Coefficient of Rolling Motion

\begin{tabular}{lll}
\hline & Quadratic coefficient & Cubical coefficient \\
$5^{\circ}$ & $3.27 \mathrm{E}-01$ & $7.37 \mathrm{E}-01$ \\
$10^{\circ}$ & $2.96 \mathrm{E}-01$ & $1.68 \mathrm{E}+00$ \\
$15^{\circ}$ & $3.25 \mathrm{E}-01$ & $6.02 \mathrm{E}-01$ \\
$20^{\circ}$ & $3.50 \mathrm{E}-01$ & $3.24 \mathrm{E}-01$ \\
\hline
\end{tabular}

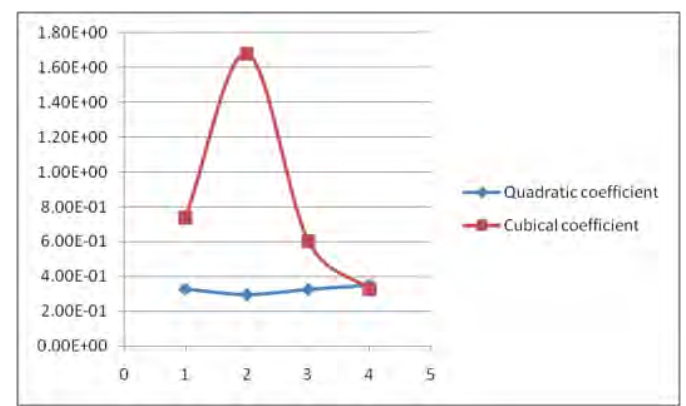

Fig.5 Curves of Non-liner Damping Coefficient of Rolling Motion

Conclusions can be drawn as follow: between $5^{\circ}$ and $20^{\circ}$, quadratic coefficient firstly decreases and then increase, cubical coefficient firstly increases and then decrease. Cubical coefficient were larger than quadratic coefficient, this point means that cubical coefficient influence function value greater than quadratic coefficient.

\section{Results and Analysis of Pitching Motion}

The pitching motion experiments were designed similar to rolling motion, but the initial angle designed between $2^{\circ}$ and $6^{\circ}$. These initial angles are reasonable to planing boat. The experimental process was same with roll ones. Result was show as follows:

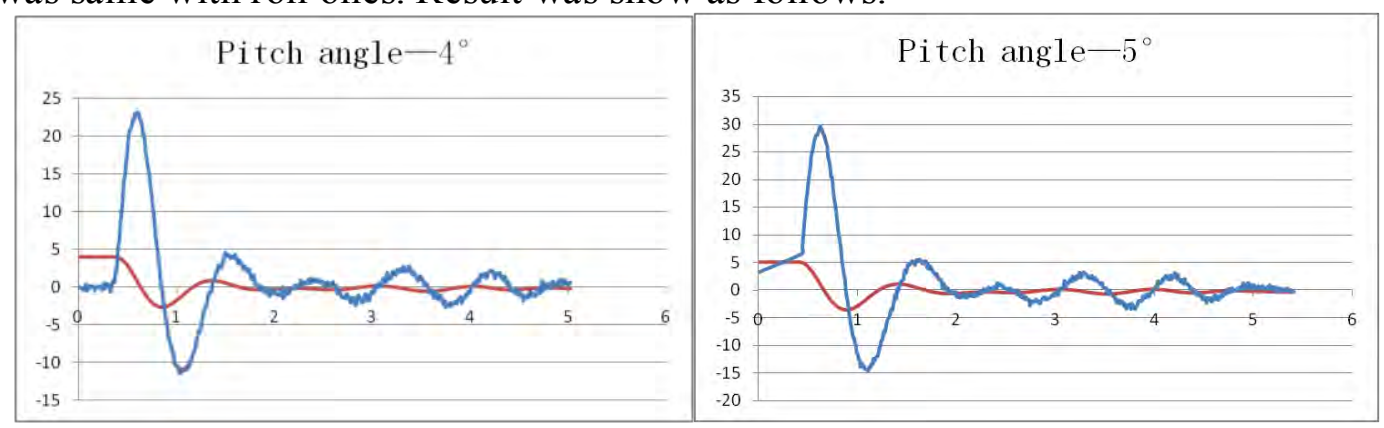

Fig. 6 Different Initial Pitch Angle Decay Curves

The four pictures above show different decay pitching angle and pitching angular velocity. From figures can draw this conclusion: free pitching decay frequency is consistent at the first period.

As the figure above, when the initial pinch angle was $6^{\circ}$, its period was disorder, maybe affected by worker or the flexible data cable (disposed along the longitudinal) influenced when pitch angle was large. In addition, pinching and heaving of coupling effect was also taken into consideration. 
After analyzing the period of pitching motion, using identification program can we get damping coefficient of pitching motion of the planing boat. Quadratic coefficient and cubical coefficient are set out as following form and figure.

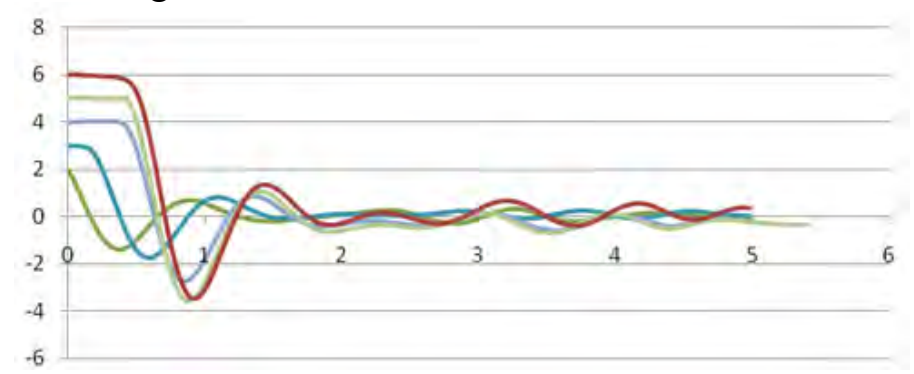

Fig. 7 The Comparison Chart of Free Pitching Decay

Tab. 3 Non-liner Damping Coefficient of Pitching Motion

\begin{tabular}{llll}
\hline & Quadratic coefficient & Cubical coefficient \\
\hline $2^{\circ}$ & & $3.16 \mathrm{E}-01$ & $4.98 \mathrm{E}+00$ \\
$3^{\circ}$ & $3.98 \mathrm{E}-01$ & $4.63 \mathrm{E}+00$ \\
$4^{\circ}$ & & $4.79 \mathrm{E}-01$ & $1.12 \mathrm{E}+00$ \\
$5^{\circ}$ & & $3.91 \mathrm{E}-01$ & $1.54 \mathrm{E}+00$ \\
$6^{\circ}$ & & $8.55 \mathrm{E}-01$ & $1.77 \mathrm{E}+00$ \\
\hline & & & \\
\hline & & & \\
\hline
\end{tabular}

Fig. 8 Non-liner Damping Coefficient of Pitching Motion

Conclusions can be drawn as follow: between $2^{\circ}$ and $6^{\circ}$, quadratic coefficient firstly decreases tortuous, cubical coefficient firstly decreases and then increase. Cubical coefficient were larger than quadratic coefficient, this point means that cubical coefficient influence function value also greater than quadratic coefficient in pinching motion.

\section{Results and Analysis of Different Draft}

Comparison of the same initial rolling angle or pitching angle in different draft.

(1) Analysis the rolling motion of different draft, as following:

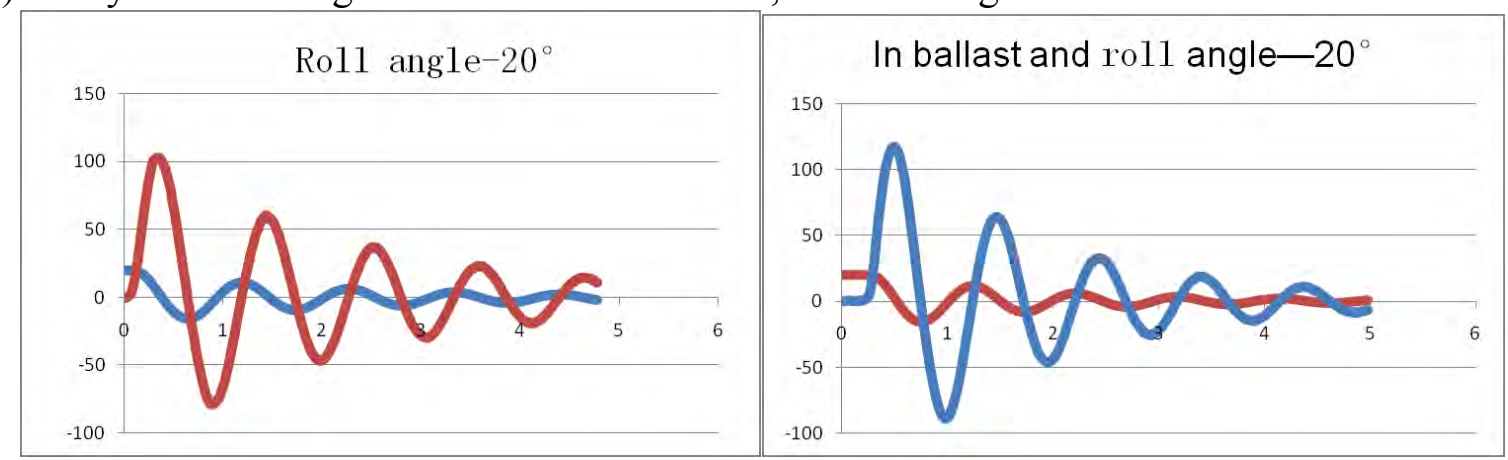

Fig. 9 Decay Curves of Different Initial Roll Angle and Draft 
Through compare with the figures above, we can draw this conclusion: The amplitude of per period in ballast roll state is greater than without ballast status. After analysis this phenomenon, we found that under a large inertial force the speed of reducing magnitude became slow.

(2)Analysis the pitching motion of different draft, as following:

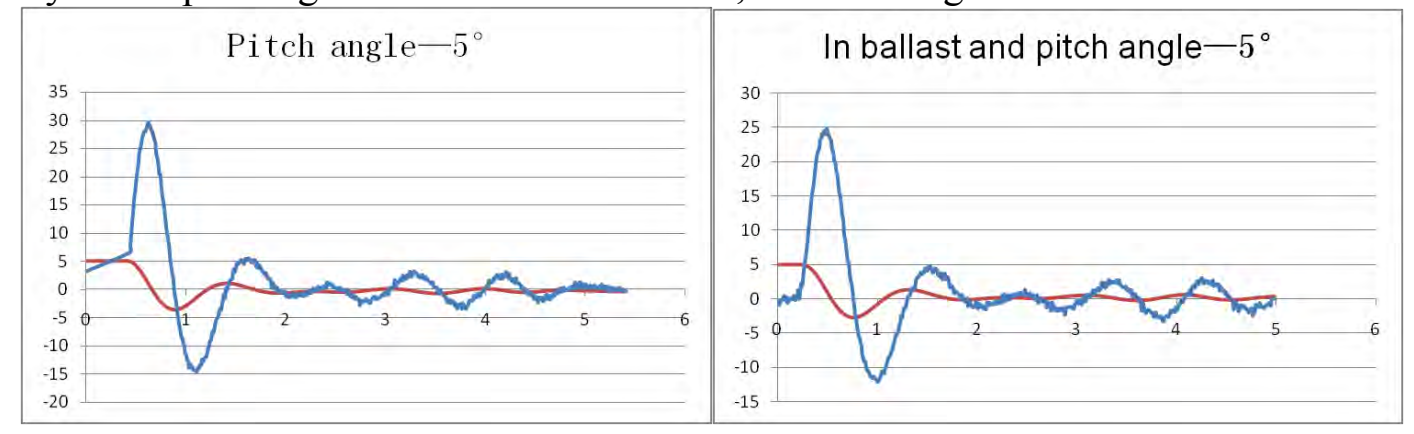

Fig. 10 Decay Curves of Different Initial Pitch Angle and Draft

Opposite with rolling motion, pitching motion in ballast has larger decrease amount. Because planning boat in ballast, the influence caused by Iy larger than force, so can see the opposite condition.

\section{Conclusions}

The experiments on rolling motion, different draft and initial angle were set to meet researching. After the identification and determine the coefficients, can draw these conclusions:

(1) different initial roll angle have the same decay frequency;

(2) in ballast rolling motion have longer decay time than no ballast condition;

The experiments on pitching motion researching also be taken. We can draw these conclusions:

(1) different initial pinch angle have the same decay frequency in first several period;

(2) the influence of pitching motion caused by Iy is larger than force.

\section{Acknowledgement}

This research was financially supported by National Natural Science Foundation of China: 51379094.

\section{References}

[1]Adrian S. Onas, Raju Datla: Non-liner roll motions of a frigate-type trimaran, 2011.

[2]Yao Di, Lu Xiaoping, Wang Yi. Trimaran model rolling test and its performance analysis [J]. Chinese Journal of ship research, 2010, 04: $6-11+26$.

[3]Liu Yuchen, Ren Yi, Cai Xin Gong, Wang Ping. Researching on rolling motion of trimaran model[J].Chinese Journal of ship research, 2011, 02:20-23.

[4]Zhu Feng. Preliminary Research on Pattern of Shaking Movement of Composite Three-body USV. [D] Jiangsu University of Science and Technology: 2012.

[5]Ye Jianhua. Process Identification Techniques [J]. Shanghai: Shanghai University Press, 2007, 59

-82.DOI:10.1364/JOCN.1.00A170.

[6]Venkataramanan Balakrishnan. System identification: theory for the user (second edition)[J]. Automatica, 2002, 382.

[7]Ayman B. Mahfouz. Identification of the nonlinear ship rolling motion equation using the measured response at sea[J].Ocean Engineering,2004, 31(17/18):2139-2156. 